\title{
Una mirada sobre el centro de interés mitos populares en estudios de disponibilidad léxica de Resistencia y Corrientes
}

Hugo Roberto Wingeyer Jimena Verónica Gusberti

\section{Resumen}

Analizamos en el presente artículo aspectos del relevamiento del léxico sincrónico de las ciudades de Resistencia y Corrientes. Se trata de los campos semánticos: El campo y Mitos populares, correspondientes a los resultados de la metodología estadística de la disponibilidad léxica. Más concretamente, se indaga sobre la construcción del centro de interés: Mitos populares. Sobre la base de la sistematización de sus unidades, intentamos clarificar lo que interpretaron nuestros informantes por mito popular. Por último, nos centramos en el análisis de los términos de mayor frecuencia de aparición.

\section{Palabras clave}

léxico - estadística - disponibilidad - palabra - vocablo - frecuencia - mito - polpular

\section{Introducción}

En el año 2007, sobre la base de 500 pruebas asociativas recogidas en el ańo 2001, completamos la identificación del léxico disponible de Resistencia y, en el año 2008, aplicamos, en la ciudad de Corrientes ${ }^{85}$, 500 encuestas a alumnos del último curso de escuelas públicas y privadas con el mismo propósito: la identificación del léxico disponible. Para su cálculo, realizado sobre el procesamiento de las pruebas formadas por temas o centros de interés que intentan cubrir un amplio espectro de intereses humanos, hemos utilizado el programa LEXIDISP.

En el presente trabajo analizamos la construcción de sentido del centro Mitos populares, en las pruebas de la ciudad de Corrientes, y su relación con unidades del caudal léxico del tema El campo, recogido tanto en los informantes correntinos como resistencianos. Intentamos explicar aquí las operaciones que entran en juego en la asociación de términos, desde el marco teórico de la semántica de los prototipos, propuesto por Kleiber, a partir de la idea de "efecto prototípico".

\section{Marco teórico}

El programa utilizado para el cálculo de la disponibilidad léxica, auspiciado por la Universidad de Alcalá y la Asociación de Lingúistica y Filología de América Latina, se basa en la aplicación de pruebas asociativas, que son conjuntos de temas o centros de interés en los que

${ }^{85}$ Se trata de dos Proyectos de Investigación acreditados en la Secretaria General de Ciencia y Técnica de la UNNE: Léxico disponible de Resistencia (2006-2007) y Léxico disponible de Corrientes (2008-2009). 
el informante vuelca todos los términos relacionadas con cada uno de ellos. Términos que se clasifican en palabras, que son todas las unidades recogidas, repetidas o no, y vocablos que son cada una de las entradas diferentes. El índice de disponibilidad surge de la combinación de la frecuencia de aparición y de la posición que ocupa cada uno de los vocablos. Son diecisiete los temas considerados por nosotros y en la mayoria de los trabajos de disponibilidad; a los que en Corrientes hemos decido incorporar otros, como el de Mitos populares. La idea de incluir este tema surgió de las observaciones, en los resultados de la disponibilidad léxica de Resistencia, del tema El campo, en el que los informantes registran, en general, lo que se les presenta como opuesto a al centro inmediato anterior, $\mathrm{La}$ ciudad; porque aparecen alli términos que se relacionan con el mundo de seres imaginarios de origen guarani y mitos populares.

Por otro lado, como necesitamos medir el grado de coincidencia de las respuestas obtenidas en los temas en cuestión, aplicamos el Índice de Cohesión ${ }^{86}$; observamos así, en estos campos semánticos, el carácter más cerrado de las veinte primeras unidades más disponibles, en relación con las del resto, ya que la variación en las respuestas es mínima.

Así, a partir de los datos obtenidos en las pruebas asociativas, motivadas por el nombre del centro de interés, podemos indagar sobre las posibilidades que presenta esa asociación con la semántica de los prototipos. Desde la perspectiva de la metodología de la disponibilidad léxica, el centro de interés o categoría, en términos de Kleiber, se construye, en el momento de aplicar las encuestas, sobre la base del pedido realizado al informante de que escriba todo lo que le sugiere el mismo. En la teoría elegida, el prototipo no es una unidad central que represente determinada categoría más bien "contradice la teoría de los rasgos distintivos, que intenta definir la pertinencia a una clase (ya sea palabra, acto o acontecimiento) en términos de un grupo de rasgos discretos o propiedades" (Duranti, 2000:67). Kleiber habla de "efecto prototípico" que es la activación en los actores sociales de las relaciones asociativas entre las unidades que configuran cada campo semántico propuesto. A partir de la lectura de las mismas, podremos acceder a atributos básicos (pertinentes) que les son comunes, y que estructuran dicha categoría. En otras palabras, "la finalidad de las experiencias y de las pruebas realizadas es señalar efectos prototípicos y no poner de manifiesto la estructura misma de las categorías" (1990:144).

Por último, en esta teoría semántica se plantea la problemática compleja de la pertinencia, establecida en el nivel de nuestros informantes, para las categorías seleccionadas. Hablamos de complejidad de la pertinencia por la permanente mutabilidad de los efectos prototípicos. Por ejemplo, si comparamos las listas de vocablos de la disponibilidad léxica de Corrientes con las de Resistencia, en el tema: El campo, aparecen vocablos disímiles como pobreza, niño sucio, piojo y mugre, que revelan la visión que algunos informantes tienen del espacio rural en esa comunidad de habla, tanto como conflicto, piquetero, ruralista y de angelis registradas después de la coyuntura nacional de conocimiento público.

\footnotetext{
${ }^{86}$ Este índice (con escala del 1 al 0), que se obtiene dividiendo el promedio de respuestas de cada sujeto por el número de palabras diferentes, será menor cuando mayor variación exista en las respuestas. Informa si el centro analizado es cerrado o difuso. Ha sido elaborado por M. Echeverria $(1987,1991)$.
} 


\section{Análisis del corpus}

Como decíamos, el centro de interés mitos populares corresponde a una segunda etapa en la recolección de datos. Es interesante que su núcleo proponga vocablos tan diversos en cuanto a ámbitos y representaciones como pombero, lobizón, gauchito gil, drácula, el viejo de la bolsa, chupacabras, reyes magos, brujas, el monstruo del lago ness, el ratón pérez, papá noel, gilda y antojos durante el embarazo. Dado este amplio registro, intentamos sistematizar los vocablos a partir de zonas de sentido que den cuenta, de algún modo, qué interpretaron los informantes por "mitos" y por "populares". Así, obtuvimos:

1. Creencias religiosas

a- de tradición católica: reyes magos, ángeles, santos, san expedito, san jorge, san baltazar, santa catalina, la cruz de los milagros, dios, diablo, jesús, vírgenes, virgen de itati, virgen maría, adán y eva;

b- de otras religiones, sectas y hasta grupos sociales: gitanos, evangelios, testigos de jehová, umbandistas, pai, mai, mormones, judios, macumba, el corán;

c- de raigambre guaraní el pombero o pomberito, yasí yateré, la pora, pata de lana, karaí octubre;

d- de otras tradiciones: papá noel (santa claus), duendes, hadas, espiritus.

2. Creencias pavorosas, supersticiones:

a-personajes: lobizón, cuco, brujas, la llorona, la luz mala, monstruos, fantasmas, vampiros, la muerte, espectros, zombis, la yeta, la ura, ratón pérez;

b-prácticas: gualicho, payé, tabla wija, macumba, barrer de noche, molestar a los muertos;

c-dichos: las pastillas anticonceptivas engordan; tener antojos durante el embarazo y que los bebés nazcan con una mancha.

3. Cultos (que participan del sincretismo religioso nacional): gauchito gil, san la muerte; la difunta correa.

4. Leyendas urbanas: el viejo de la bolsa, la vieja de la escoba, la dama de blanco, la degolladita, el charanguito, la loca del palo, el kolimba, el potro, el tacuara.

5. Relatos y personajes presuntamente "mediatizados" por la escolarización, y los medios masivos:

a-de leyendas argentinas: el carau, el pitogüé, el crespin, la urraca, el camalote, palo borracho, sauce, lapacho, chajá, cataratas del iguazú, la yerba mate;

b-de la mitología grecolatina: zeus, aquiles, hércules, poseidón, polifemo, minotauro, narciso; c-de la Literatura Infantil y Juvenil: cenicienta, caperucita roja, el gato con botas, los tres chanchitos, pinocho, peter pan, los tres mosqueteros, robin hood;

d-de series televisivas o éxito cinematográfico: chupacabras, monstruo del lago ness, el grinch, halloween, drácula, ovnis, extraterrestres, hombre lobo, jinete sin cabeza, tutankamón, la momia, pie grande, yetty, la sombra, fitz simon, mickey mouse, winnie pooh, chicas superpoderosas, topo giggio, pantera rosa, batman, gatúbela.

6. Personas veneradas por multitudes: gilda, rodrigo, maradona, madre teresa, gandhi.

7. Utopías: políticos buenos, el hombre perfecto, amor fiel, la madre maravilla. 
Si acudimos a Mircea Elíade, diremos que mito es aquello que cuenta una historia sagrada, relata un acontecimiento que ha tenido lugar en el tiempo primordial, el tiempo fabuloso de los comienzos. También, que relata cómo la realidad ha venido a la existencia gracias a algunos seres sobrenaturales.

¿Podríamos decir que este concepto se sostiene en el imaginario de los informantes? Creemos que sí, pero no se acota en él cuando un mismo estudiante ha inscripto en este campo de significados las unidades pombero y winnie pooh; en efecto, la idea de lo popular se imbrica con la de popularidad, como masividad ${ }^{87}$, también el uso común del término mito con la acepción de falsa creencia, mentira o de persona o cosa que se idealiza y pasa a ser un modelo para los demás.

Sin embargo, nuestro interés aquí no es explicar los alcances del "efecto prototípico" sino partir desde él para verificar y valorar la preeminencia de los seres guarańes en el imaginario colectivo regional, la que se hace evidente cuando la mayor frecuencia de aparición de un vocablo corresponde al personaje conocido como Pombero, más allá de las variables económicas, de edad, la ciudad, e incluso del paso del tiempo entre la primera y la segunda toma de la muestra.

Es interesante cómo este "duende sombrerudo" trasciende el ámbito rural, muta y se apropia de rasgos propios de otros seres mitológicos de raigambre guaraní; tal vez esa sea la clave de su fuerte persistencia tanto en Resistencia como en Corrientes, asociada a su carácter instrumental ; $^{88}$ "sabemos que el mito es un valor: basta con modificar sus circunstancias, el sistema general (y precario) en el que se asienta, para regular más o menos su alcance (...) si juzgamos ese mito como politicamente insignificante es, simplemente, porque no fue hecho para nosotros. (Barthes, 1999:241)

Si bien la tradición oral regional lo ubica en zonas riberefias por ser "primitivo protector de la naturaleza", lo es especialmente de las aves del monte; de alli que persigue y castiga a nińos "ruideros" que cazan pájaros en horas de la siesta; aun en la actualidad el relato de sus andanzas es motivo suficiente para atemorizar a los niños de las ciudades y asi "obligarlos" a dormir o permanecer dentro de las casas en ese horario hostil. Por otra parte, no es un dato menor que en épocas más recientes sus intereses se tornen eminentemente eróticos, lo que lo hace circular también en horas de la noche y "en las últimas décadas lleva su desprestigiada fama hasta zonas urbanas". (Acosta, 2000: 8)

\footnotetext{
${ }^{87}$ Sería motivo de un estudio más pormenorizado la aparente diferenciación -o igualación en cuanto a jerarquía sintáctica- de los términos mitos y populares en la construcción que se presenta en las encuestas como título del centro de interés: mitos populares. En todo caso, y siguiendo a Barthes, intuimos que la propuesta de Winnie Pooh como popular partiría de la naturalización de su consumo: "estas formas 'normalizadas' llaman poco la atención (...) se incorporan a la masa enorme de lo indiferenciado, de lo insignificante, en suma de la naturaleza" (Barthes,1999: 235)

${ }^{88}$ Según el Prólogo a Mitologia Guarani, "cincuenta años atrás era común que en las familias de clase media resistenciana, el embarazo de una mujer soltera fuera desintegrador del núcleo. (...) El conflicto se planteaba dentro de una cultura que enfrentaba tesoneramente una férrea moral, a todo lo consideraba pecado, era real y de consecuencias trágicas. En los estratos de cultura rural y de vertientes aborígenes, como la guarani, existía la creencia de mitos armonizadores como la del Pombero, que podía poseer y embarazar a una mujer sin su consentimiento, y sin que lo pueda evitar. (...) promueven la continuidad del grupo. El embarazo no fue pecado: fue el Pombero, un ser mitológico, un duende" (Acosta 2009: 5-6)
} 
En este sentido se asocia con la conducta inmoral que históricamente la tradición le atribuye al Pata de Lana o Py-rague, también aquí registrado en la periferia de este centro de interés. Este "enano diabólico, pelado y lampino, que anda desnudo (...) se desliza de un lugar a otro sin hacer ruido al caminar, pues cubre sus pies, de pequeñas pezuñas, con una especie de botita de lana o cuero de oveja"; tiene predilección por el lecho de mujeres despechadas 0 esposas enojadas. (Acosta, 2000:16)

Los aficionados a la pesca $-y$, a menudo, al relato de fogón- hacen referencias constantes en su repertorio anecdótico a las molestias que puede causar el Pombero remedando el canto de las aves o emitiendo su característico silbido, si no se le tributan tabaco y miel. En este punto se advierte la identificación parcial del mismo con otro duende "ligeramente travieso y maligno": el Yasí Yateré -el que aparece en una frecuencia muy menor en nuestras encuestas-. Coincidentemente, "su costumbre es robar miel y tabaco a desaprensivos viajeros", pero pocas veces "se muestra a orillas del monte con la figura de un nifio", con lo cual, creemos, limita notoriamente las posibilidades narrativas de los agentes transmisores orales. (Acosta 2000: 10)

Una mención escrita de su existencia es registrada en la narrativa de Horacio Quiroga: "Yo no logré ver nunca un Yaciyateré. Of su canto en la noche, pero no ví sus bucles de oro ni su bastón, ni le ví robar a las criaturas, para abandonarlas luego enloquecidas por su contacto" reza el primer párrafo de su artículo para Caras y Caretas publicado el 3 de enero de 1925. Allí también consigna que a este singular duende "se inculpa el ciento por ciento de las meningitis infantiles". (Quiroga, 1998: 28)

Este escritor también reelabora la versión regional de El vampiro: "Acababa una noche de dormirme, cuando fui despertado por un vampiro. El animal volaba a diestra y siniestra por un galpón y sus aletazos sonaban como látigos al cruzar a mi lado"; en esta crónica, también de 1925, describe además: "los vampiros apartan el pelo con el hocico, adhieren la boca a la piel, y mientras entreabren las alas con breves sacudidas, van absorbiendo gota a gota la sangre de sus amigos" (Quiroga, 1998: 30) Es notoria en la actualidad su filiación con personajes de otras tradiciones literarias -como Drácula- por lo que no reviste especial interés para nosotros aquí.

Con menor Índice de Cohesión se registra, sin embargo, Karai Octubre, quien por su figura, se parece al Pombero (viejo, petiso, con enorme panza cubierta de vellos y portador de amplio sobrero). "Tiene el hábito de salir todos los días $1^{\circ}$ de octubre, hacia media mafiana, y recorrer los poblados con el fin de observar si los responsables de cada hogar han reunido comida suficiente para pasar sin sobresaltos la época de la miseria que, antiguamente, comenzaba ese día y terminaba el 24 de diciembre" (Acosta, 2000: 20) Tal vez este relato fuese funcional en otros momentos de la cultura popular argentina y la pérdida de su registro entre nuestros jóvenes informantes devenga de la imposibilidad de sostenerlo desde su propia narrativa: ¿puede hoy la tradición ponerle una fecha de inicio y finalización anual a la miseria?

En este caso también es destacable el modo en que la caracterización del "Señor de Octubre" se subsume en la figura predominante del Pomberito.

Nuestro análisis concluye con El Lobizón, segundo en frecuencia en el corpus en cuestión. En la extensa población de seres imaginarios que Adolfo Colombres sistematiza, lo sitúa entre aquellos que vienen de Europa -como el Basilisco, las Brujas, las SirenasConsiderar los orígenes y variaciones de este personaje ya universal excede nuestra propuesta; 
otros lo han hecho amplia y documentadamente y en ellos abrevaremos para dar cuenta sólo de los matices que presenta en la tradición del NEA ${ }^{89}$.

Según el historiador local Ertivio Acosta, los guaraníes creían en el Yaguareté Abá (hombre-tigre), pero "el Lobizón, con los caracteres conocidos, ingresa al Litoral desde las costas brasileñas del río Uruguay" (Acosta, 2000: 22). Por otra parte, la existencia en nuestra fauna local del aguará guazú -en guaraní "zorro grande"- propicia la identificación de este ejemplar con la figura del Hombre-lobo de la tradición, ya transfigurado en bestia. Así, una vez más lo registra en sus Crónicas Quiroga: "rarísimo animal del bosque, huraño y sombrío a más no poder, y cuyo singular aspecto puede definirse diciendo que es un zorro rojizo, con altisimas patas de lobo (...) marcha avanzando a un tiempo las patas del mismo lado, y no cruzadas, como es la norma en todos los cuadrúpedos (...) Con su flacura, sus largas patas, sus orejas de punta y su largo andar, puede muy bien este aguará dar en un crepúsculo de selva la impresión de un espectro" (Quiroga 1998: 56). No es extraño que se haya extinguido ya en algunos lugares del noroeste chaqueño, dada la destrucción de su hábitat (grandes extensiones de pasturas para el ganado) pero también la configuración del mito en su aspecto y costumbres, lo que le ocasiona implacable persecución y muerte.

La vigencia de la creencia en la zona de esta metamorfosis se registra también en textos periodísticos. El equipo de investigación de nuestra universidad conducido por la Prof. Norma Porto, documenta, entre 2000 y 2009, diez noticias que dan cuenta de la aparición, avistamiento e incluso captura del temido Lobizón. El Diario Norte de la ciudad de Resistencia presenta como titular del 21 de febrero de 2004: "Un lobizón conmocionó las calles de Sáenz Peña"; también se leen en la sección Policiales del 23 de junio de 2000: "Concepción del Bermejo Convulsionada por la aparición del Lobizón", así como la más reciente del 16 de septiembre de 2008: "Afirman que en Misiones vivió un Lobizón almacenero", cuya volanta agrega: "Pacto de silencio entre pobladores que se prolongó por 60 años". El abordaje y recopilación de las resemantizaciones de este mito en la zona litoraleña se acompaña en esta investigación con veinte relatos de informantes orales de Chaco y Corrientes, y una sistematización de las proyecciones literarias del mismo, ya a nivel local como nacional, fundamentalmente en la recopilación -en curso- que la Prof. Natalia Trevisán registra en autores de Literatura Infantil y Juvenil, como Elsa Bornemann, Beatriz Actis, Nicolás Schuff, Graciela Cabal, Hugo Mitoire, entre otros.

\section{Conclusión}

$\mathrm{Si}$, como dice Barthes, existe una geografia social de los mitos y un mito madura porque se extiende (Barthes, 1999:246), este avance respecto del análisis del caudal léxico recogido en los centros de interés el campo (2001) y a partir de él, mitos populares (2008) da cuenta de que situaciones coyunturales, diferencias socioeconómicas y otros relevantes aspectos de las realidades de las ciudades de Resistencia y Corrientes no han modificado la persistencia y preeminencia de los seres mitológicos guaraníes que pueblan el imaginario colectivo regional.

\footnotetext{
${ }^{89}$ Trabajos publicados en el marco del Proyecto "Persistencia y transformación del mito de la metamorfosis del hombre en lobo, en relatos de la literatura latina y en producciones literarias y cinematográficas argentinas", acreditado en la Secretaria General de Ciencia y Técnica de la UNNE (2005-2008).
} 
Futuras miradas podrán tal vez explicar lo que aquí aún no: otras posibilidades y niveles de representación de nuestro centro de interés que analicen la relación entre el "efecto prototípico" y la llamada cultura de masa.

\section{Referencias}

ACADEMIA ARGENTINA DE LETRAS, 2003, Diccionario del habla de los argentinos, Academia Argentina de Letras.

ACOSTA, Ertivio, 2000. La riquísima mitología guarani desde sus personajes diabólicos.

Documentos Culturales $\mathrm{N}^{\circ} 3$. Subsecretaría de Cultura de la Provincia del Chaco.

ACOSTA, Ertivio, 2009. Mitologia Guarani. Museo del Hombre Chaqueño "Prof. Ertivio Acosta", Instituto de Cultura del Chaco.

AYORA ESTEBAN, M. Carmen, 2006, Disponibilidad léxica en Ceuta: aspectos sociolingüisticos, Cádiz, Universidad de Cádiz.

BARTHES, Roland, 1999. Mitologías, Siglo XXI. 12a Edición.

COLOMBRES, Adolfo, 2002. Seres mitológicos argentinos. Bs As, Emecé.

CONDE, Oscar, 2004, Diccionario etimológico del lunfardo, Buenos Aires, Taurus.

DURANTI, A., 2000, Antropología linguística, Madrid, Cambridge University Press.

ECHEVERRfA, Max S., 1987, "Disponibilidad léxica en Educación Media. Resultados cuantitativos", en VII Seminario de Investigación y Enseñanza de la Lingüistica, Valparaíso, Ediciones Universitarias de Valparaiso, pp. 102-116.

ECHEVERRf́A, Max S., 1991, "Crecimiento de la disponibilidad léxica en estudiantes chilenos de nivel básico y medio", en H. López Morales (ed.), La enseñanza del español como lengua materna, Río Piedras, Universidad de Puerto Rico, pp. 61-78.

ELIADE, Mircea, 1981. Mito y realidad. Barcelona, Guadarrama.

GALLOSO CAMACHO, María V., 2003, El léxico disponible de Ávila, Salamanca y Zamora, Burgos, Fundación Instituto Castellano y Leonés de la Lengua.

GÓMEZ MOLINA, José R. y Gómez Devís M. ' B., 2004, La disponibilidad léxica de los estudiantes preuniversitarios valencianos, Valencia, Universitat de València.

GONZÁLEZ MARTÍNEZ, Adolfo E., 2002, La disponibilidad léxica de los alumnos preuniversitarios de la provincia de Cádiz, Cádiz, Universidad de Cádiz.

HAENSCH, Gunter y Reinhold Werner, 2000, Diccionario del Español de Argentina. Español de Argentina - Español de España, Madrid, Gredos. (DEArg)

KLEIBER, Georges, 1990, La semántica de los prototipos. Categoría y sentido léxico, Madrid, Visor.

LÓPEZ CHÁVEZ, Juan, 1992, “Alcances panhispánicos del léxico disponible”, Lingúística, 4, pp. 26-124.

LÓPEZ MORALES, Humberto, 1989, Sociolingüistica, Madrid, Gredos.

LÓPEZ MORALES, Humberto, 1994, Métodos de investigación lingüistica, Salamanca, Ediciones Colegio de España.

LÓPEZ MORALES, Humberto, 1995, "Los estudios de disponibilidad léxica: pasado y presente", en Boletín de Filología de la Universidad de Chile 35, pp. 245-259. 
LÓPEZ MORALES, Humberto, 1999, Léxico disponible de Puerto Rico, Madrid, Arco Libros. LOTMAN, Iuri M., 1996, La semiosfera (Tomos I y II), Ediciones de Desiderio Navarro, Madrid, Ediciones Cátedra.

LYONS, Johns, 1995, Semántica lingüistica. Una introducción, Trad. Santiago Alcoba, Paidós, Barcelona.

MATEO GARCÍA, María V., 1994, "Disponibilidad léxica: posibles aplicaciones", en Actas de las Primeras Jornadas sobre estudio y enseñanza del léxico, Granada, Universidad de Granada, pp.141-147.

MATEO GARCÍA, María V., 1996, Estratificación social del léxico de la alimentación en Motril (Granada), Almería, Universidad de Almeria.

MATEO GARCÍA, María V., 1998, Disponibilidad léxica en el C.O.U. almeriense. Estudio de estratificación social, Almeria, Universidad de Almería.

MORENO FERNÁNDEZ, Francisco, José E. Moreno Fernández y Antonio J. García de las Heras, 1995, "Cálculo de disponibilidad léxica. El programa LexiDisp", en Lingüística 7, pp. 243-249.

PORTO DE FARÍAS, Norma y TREVISÁN, Olga Natalia, 2008. "El mito del hombre en lobo: del versipellis latino al lobisón en cuentos argentinos contemporáneos". Cuadernos de Literatura $N^{\circ} 12$. Resistencia, Facultad de Humanidades de la UNNE.

QUIROGA, Horacio, Crónicas del Bosque, Cántaro Editores, 1998.

REAL ACADEMIA ESPAÑOLA, 2001, Diccionario de la lengua española, Madrid, Espasa Calpe. (DRAE)

REAL ACADEMIA ESPAÑOLA, <http:// www.rae.es/ > (Consultado el 1 de agosto de 2008). WINGEYER, Hugo R., 2007, Léxico disponible de Resistencia, Departamento de Filología de la Facultad de Filosofia y Letras de la Universidad de Alcalá, Alcalá de Henares, Tesis Doctoral inédita.

WINGEYER, Hugo R. y Angelina Alejandro B., 2008, "Resultados de la disponibilidad léxica de Corrientes y Resistencia: Comparaciones desde un abordaje semántico de los términos referidos a 'El campo'", en las Actas del IV Congreso Nacional Sobre Problemáticas Sociales Contemporáneas, Universidad Nacional del Litoral.

Hugo R. Wingeyer es Profesor en Letras por la Universidad Nacional del Nordeste. Posee una Maestría y un Doctorado en Linguística Aplicada por la Universidad de Alcalá de Henares, España. Dirige los proyectos de investigación Léxico disponible de Resistencia (2006-2007) y Léxico disponible de Corrientes (2008-2009). Se desempenfa como Profesor Adjunto en las cátedras de Historia del Español y Lingüistica I en la carrera de Letras de la UNNE.

Jimena V. Gusberti es Profesora en Letras por la Universidad Nacional del Nordeste. Posee una Maestría en Promoción de la Lectura y la Literatura Infantil por la Universidad de CastillaLa Mancha, Espana. Participa desde 2006 en los proyectos de investigación dirigidos por el Dr. Hugo Wingeyer. Se desempeña como Profesora Adjunta en el Taller de Comprensión y Producción de Textos que se imparte a seis carreras de la Facultad de Humanidades de la UNNE. 